\title{
1 The Role of IgG3 in Infectious Diseases
}

3 Timon Damelang*, Stephen J. Rogerson ${ }^{\dagger}$, Stephen J. Kent* and Amy W. Chung*

$4{ }^{*}$ Department of Microbiology and Immunology, ${ }^{\dagger}$ Department of Medicine, both at The

5 Peter Doherty Institute for Infection and Immunity, University of Melbourne,

6 Melbourne, VIC, Australia

7 Correspondence: awchung@unimelb.edu.au

8

9 Keywords: IgG3, antibody, complement, ADCC, glycosylation, allotypes,

\section{Abstract}

12 Immunoglobulin IgG3 comprises only a minor fraction of IgG in human plasma and 13 has remained relatively understudied until recent years. Key physiochemical 14 characteristics of IgG3 include an elongated hinge region, greater molecular flexibility, 15 extensive polymorphisms and additional glycosylation sites not present on other lgG 16 subclasses. These characteristics make IgG3 a uniquely potent immunoglobulin, with 17 the potential for triggering effector functions including complement activation, 18 antibody-mediated phagocytosis or antibody-mediated cellular cytotoxicity. Recent

19 studies underscore the importance of $\operatorname{lgG} 3$ effector functions against a range of 20 pathogens and have provided approaches to overcome IgG3-associated limitations,

21 such as allotype-dependent short antibody half-life and excessive pro-inflammatory 22 activation. Understanding the molecular and functional properties of IgG3 may 23 facilitate the development of improved antibody-based immunotherapies and vaccines 24 against infectious diseases. 
27 Antibodies $(\mathrm{Ab})$ play a major role in protection against infections by binding to and inactivating invading pathogens. Although IgG3 constitutes a minor proportion of total human immunoglobulins ( $\lg )$, a growing number of recent studies have highlighted $\lg \mathrm{G} 3$ as critical for the control and/or protection of a range of pathogens, including viral (eg HIV [1-5]), bacterial (eg Neisseria Spp [6-8]) and parasitic (eg. Plasmodium Spp. [9-13]) pathogens. This review will describe the unique characteristics of human IgG3 that contribute to its potent anti-pathogenic functions including enhanced neutralization, FcyR affinity and Fc-mediate activity. Furthermore, we will discuss how the unique properties of IgG3 can be harnessed for future preventative and therapeutic manipulations and highlight the major obstacles and outstanding questions that are pertinent.

\section{Human IgG3: a unique but understudied antibody subclass}

The glycoprotein $\lg G$ is the most abundant isotype in healthy human plasma, and can be separated into four subclasses: IgG1 (60-70\% in plasma), IgG2 (20-30\%), IgG3 (5-8\%) and IgG4 (1-3\%) [14]. The amino acid sequences of the human $\lg G$ subclasses are $>95 \%$ homologous in the constant domains of their heavy chains (Fig.1). IgG3 has a distinct amino acid composition and structure to the 'hinge region' (see Glossary) between $\mathrm{C}_{\mathrm{H}} 1$ and $\mathrm{C}_{\mathrm{H}} 2$ [15]. The flexibility of the hinge region decreases in the order $\lg G 3>\lg G 1>\lg G 4>\lg G 2$ [16]. Further, $\lg G 3$ has an extended hinge region (Fig. $1+$ Tab. 1), consisting of up to 62 amino acids, forming a poly-proline double helix consisting of 11 disulfide bridges (compared to two in hinge regions of IgG1 and IgG4 and four in hinge region of IgG2) [17]. This is the result of duplications of a hinge exon, encoded by one single exon in $\lg G 1$, $\lg G 2$, and $\lg G 4$, but up to four exons in 
51 IgG3. The extended hinge region of IgG3 expands the Fab arms further away from

52 the Fc. This distance enables high rotational freedom which provides the molecule

53 with greater flexibility and reach [18]. The longer hinge region and the greater reach

54 of the Fab arms together might explain why this subclass can probe into less exposed

55 antigens and could contribute to IgG3's high potential to activate effector functions [17, 56 18].

It is important to note that the structure and enhanced functionality of human $\lg G 3$, is unique compared to most animal models, including murine and macaque species,

60 which do not have an equivalent analogue among its IgG subclasses [19-21]. This is 61 particularly relevant for non-human primate models, where macaque spp. are commonly used for pre-human clinical trials and may historically have contributed to the why the importance of human $\lg G 3$ is understudied in comparison to other $\lg G$ 64 subclasses.

\section{Allotypes of IgG3}

Allotypes are polymorphisms in the constant regions of Ig heavy and light chains (Fig. 1b). IgG3 is the most polymorphic subclass with thirteen $\mathrm{Gm}$ allotypes termed G3m, which is thought to be due to its higher rapid evolutionary diversification compared to other subclasses [17]. G3m allotypes are inherited in different combinations or G3m alleles (encoded by one or several IGHG3 alleles) shared among individuals within populations (Tab. 2). Several G3m allotypes consist of a combination of multiple amino acids, which lead to changes of their tertiary protein structures, with all known $\mathrm{G} 3 \mathrm{~m}$ allotypes located within the $\mathrm{C}_{\mathrm{H}} 2$ and $\mathrm{C}_{\mathrm{H}} 3$ domains[22]. 
$\lg$ G3 allotypic variations can have structural and functional consequences, such as a shorter hinge regions and extended half-life compared to other allotypes [23, 24]. In addition, polymorphisms in the $\mathrm{C}_{\mathrm{H}} 3$ domain affect the $\mathrm{C}_{\mathrm{H}} 3-\mathrm{C}_{\mathrm{H}} 3$ interdomain interactions [25], with potential consequences for $\mathbf{C 1 q}$ binding in complement activation [25, 26]. Specific allotypes also contribute to underappreciated difficulties in purifying human IgG3 from serum samples, where only allotypes containing a histidine residue at position 435 can be purified by protein $A$ [27].

\section{Glycosylation of lgG3}

Glycosylation is a post-translational modification of IgG Abs, which can be regulated by a range of B-cell stimuli, including environmental factors, such as stress or diseases, cytokines and innate immune signaling receptors, such as Toll-like receptors. Hence, exposure to specific pathogens, antigens, or vaccination has the potential to skew Ab glycan profiles [28]. Glycosylation is an inherent mechanism of $\mathrm{Ab}$ diversification, on top of $\mathbf{V}(\mathrm{D}) \mathbf{J}$ recombination, somatic hypermutation (SHM) and class switch recombination (CSR), and thereby contributes to the extent of the Ab repertoire of B-cells [29].

IgG3 Abs can include up to three potential glycosylation sites. The most well-described glycosylation site is found in all human IgG subclasses, where carbohydrate groups are attached to asparagine 297 in the $\mathrm{C}_{\mathrm{H}} 2$ domain (Fig. 1c). The glycans at this $\mathrm{N}$ glycosylation site can influence Ab stability [30], binding to Fcy-receptors (FcyRs) and complement [31], consequently modulating effector functions, such as complement-dependent cytotoxicity (CDC) and Ab-dependent cell cytotoxicity (ADCC) [32-36]. For instance, it has been shown that monoclonal IgG3 Abs expressed 
101 from a1,6-fucosyltransferase gene knockout Chinese hamster ovary cell lines, which

102 lack the ability to attach fucose to asparagine 297 of antibodies, have increased 103 binding to FcyRIIla, which enhances CDC and ADCC [26, 35]. Furthermore, a high 104 degree of agalactosylation has been associated with disease progression in various 105 infectious diseases, including HIV, Hepatitis B, Leishmaniasis and active 106 Mycobacterium Tuberculosis (TB) [37-40], while sialic acid has been linked to anti107 inflammatory activities in autoimmune diseases such as rheumatoid arthritis [41, 42].

108 A second $\mathrm{N}$-glycosylation site in heavy and light chain variable regions $\mathrm{V}_{\mathrm{H}}$ and $\mathrm{V}_{\mathrm{L}}$ have 109 been observed in approximately $15-25 \%$ of all serum IgG, which can contribute to Ab 110 stability [43], and also can modulate antigen binding, as demonstrated by a recent 111 study by van de Bovenkamp et al., where presence of Fab glycans could increase Fab 112 binging affinity up to two-fold [29].

114 Unique to $\operatorname{lgG} 3$, is the presence of O-glycosylation sites in the hinge region [44]. 115 Approximately $10 \%$ of IgG3 derived from polyclonal serum samples and $\sim 13 \%$ of 116 monoclonal IgG3 Abs have been observed to contain O-glycans [44]. Each IgG3 can 117 contain up to three O-glycans at threonine residues at triple repeat regions within the 118 hinge [44]. Indeed, the IgG3 hinge region has a high degree of surface accessibility 119 associated with O-glycosylation [45]. Surface accessibility may be responsible for the 120 slightly lower degree of O-linked glycosylation observed in recombinant G3m15 IgG3 121 with a shorter hinge region than other IgG3 allotypes [44]. Although the function of O122 glycosylation is still not fully understood, the hinge structure has been hypothesized to 123 be able to protect the Ig from proteolytic cleavage, and might also help to maintain the 124 extended conformation and flexibility of IgG3 hinge regions, though this has yet to be 125 demonstrated [44]. Clearly the role of IgG3-specific O-glycosylation is underexplored, 
126 but this is a growing area of interest, that may provide new ways to enhance the

127 potency of IgG3.

128

129 IgG3 has potent effector functions

130 IgG has a number of antigen-specific effector functions, such as immune cell-

131 activation via FcyRs, neutralization and activation of complement pathways [17, 31].

$132 \lg G 3$ is the most functional subclass, closely followed by $\lg \mathrm{G} 1$, due to its superior

133 affinity to FcyR [46]. However, IgG2 also plays an important role in targeting 134 polysaccharides and is commonly induced during bacterial infections [47], while IgG4

135 is often induced in response to allergens [48] (Tab. 1).

\section{Complement activation}

138 IgG can form complexes with C1q to activate the classical complement pathway [31], 139 while agalactosylated IgG can activate the lectin complement pathway, inducing a 140 range of functions including increased opsonophagocytosis and CDC [49, 50]. IgG3

141 binds with a higher affinity to C1q compared to other IgG subclasses (Fig. 2) [51].

142 While this activity is thought to be linked to IgG3's increased flexibility, the interaction 143 between $\mathrm{C} 1 \mathrm{q}$ and $\lg \mathrm{G} 3$ is not dependent on the length of its hinge region, as shown 144 by studies, where engineered IgG3 with shorter IgG1 or IgG4 hinge regions exhibited 145 even greater binding affinity for C1q than wild-type IgG3 [26, 44]. Instead Ab146 dependent complement-mediated lysis studies have shown that one amino acid (Lys $147322)$ in the human $\lg \mathrm{C}_{3} \mathrm{C}_{\mathrm{H}} 2$ domain is critical for $\mathrm{C} 1 \mathrm{q}$ interactions and enhanced $\mathrm{CDC}$ 148 [52]. Nevertheless, the importance of IgG3 in the lectin pathway and the relevance of 149 lgG3 glycosylation on CDC is still unknown. 


\section{FcyR binding}

152 Abs forming complexes with antigens, termed opsonization, can initiate important cell-

153 based functions such as: ADCC, Ab-dependent phagocytosis (ADP), Ab154 dependent cellular inhibition (ADCI), Ab-dependent cellular viral inhibition 155 (ADCVI), inducing the respiratory burst, triggering the release of pro- and antiinflammatory mediators and enzymes, as well as modulating antigen presentation and the clearance of pathogenic complexes (Fig. 2) [46, 53]. The efficiency of monomeric IgG3 binding to FcyRIla, FcyRIIla, and FcyRIIlb on effector cells such as neutrophils, monocytes, macrophages or natural killer (NK) is even higher than of monomeric IgG1

160 (Tab. 1) [23]. Thus, the interaction of IgG3 with FcyRs on these effector cells has been increasingly recognized as a critical immune response against a range of infectious diseases including viruses, bacteria and parasitic pathogens [1, 34, 39, 54-56].

\section{FcRn binding}

165 The interaction between $\lg$ and neonatal Fc receptors (FcRn) is important for IgG transplacental passage of IgG Abs and Ab half-life in humans $[57,58]$. FcRn binds to IgG at an acidic $\mathrm{pH}$ in the endosomes of vascular endothelial cells and recycles it back to circulation by dissociating at physiological $\mathrm{pH}$ [59]. FcRn-mediated transport of IgG3 is inhibited with the presence of IgG1 due to intracellular competition [24]. Therefore,

170 the unbound IgG3 is degraded and not returned into circulation, which in part may explain its shorter half-life in most individuals [24]. However, IgG3 affinity to FcRn is modified by an amino acid substitution at position 435, where IgG3 has an arginine instead of the histidine found in all other subclasses [24]. The R435 side chain stays

174 positively charged at physiological $\mathrm{pH}$ and can still maintain ionic interactions with

175 FcRn. This contributes to strong binding of IgG3 to FcRn at physiological pH, thus 
leading to endosomal degradation [59]. In contrast, individuals with certain allotypes

177 (Tab.2), such as G3m15 and G3m16, have a histidine at position 435. This substitution

178 makes their Ab half-life comparable to the half-life of IgG1 [24]. In fact, this means the

179 half-life of G3m15/16 is longer than that of R435 lgG3 and maternal-fetal H435 lgG3

180 transport is similar to that of $\lg \mathrm{G} 1$ [60]. This highlights the importance of histidine residues on overall binding affinity to FcRn. It must be cautioned that due to the potent ability of IgG3 to trigger effector functions, an important balance is likely required to prevent excessive pro-inflammatory responses which can cause collateral damage and over stimulation. Indeed, it has been hypothesized that the arginine substitution, which reduces the half-life of $\lg G 3$, may function to limit the potential for excessive activation and inflammatory responses, due to its more rapid clearance from circulation compared to other less inflammatory subclasses [9]. Lastly, R/H435 allotypes are relevant for infectious diseases, as discussed below.

\section{IgG3 responses to pathogens}

\section{Generation of IgG3 during various infection types}

192 IgG3 is often one of the earliest subclasses to be elicited against protein antigens upon infection [3, 61-63], due to its genetic locus positioning among Ig heavy constant chains $(I G H C)$ in humans $[64,65]$. Sequentially, IgG3 is the first IGHG gene located within the locus, followed by IgG1 (Gene order as follows: IGHG3, IGHG1, IGHA1, IGHG2, IGHG4, IGHE, and IGHA2 from 5' to 3' [64, 65]); thus IgG3 responses are often closely followed by IgG1 responses. Early lgG3 responses may be particularly beneficial for the rapid clearance of pathogens that express high levels of proteins, especially viruses, specific bacteria and parasites (discussed below), due to its potent Fc effector functions [59, 61]. Chronic infections, such as chronic HIV, in contrast, are 
often associated with a reduction in IgG3 in sera [3,63], likely due to repeated antigen stimulation and subsequent CSR to 'downstream' IgG subclasses or isotypes, which are comparatively less pro-inflammatory, due to their weaker affinity to FcyRs $[23,65]$. CSR of human $\lg$ to $\lg G 3$ in vitro is predominantly modulated by cytokines, in particular IL-4, IL-10 and IL-21 [66-69]. However the exact signals that modulate CSR in humans during various infections in vivo are not fully defined. Moreover, similar cytokines have also been linked with $\lg$ G1 CSR in vitro (IgG3 and IgG1 are the first two genes in the IGHC loci), which might potentially explain why IgG3 and IgG1 responses are often linked during infection [66-69]. Likely due to stepwise CSR events of IgG3 to

210 'downstream' IgG subclasses, analysis of clonally related lg sequences have identified less SHM within IgG3 compared to class-switched Ig subclasses, especially IgG4 [65].

\section{IgG3 in Viral Infections}

214 Virus-specific IgG3 appears early during infection, while IgG1 progressively dominates

215 the responses in most infections [46]. However, recent HIV vaccine studies suggest

216 that despite being of low titer, IgG3 Abs are potent effectors of vaccine-induced

217 humoral immune responses [2, 4, 5]. In the RV144 Phase III vaccine trial 218 (http://clinicaltrials.gov NCT00223080), the only human HIV vaccine trial to achieve 219 partial efficacy, high IgG3 binding to the V1-V2 loops of the HIV-1 Envelope (Env) 220 protein correlated with a lower risk of HIV-1 infection (i.e. increased vaccine efficacy)

221 [4]. Accordingly, the depletion of IgG3 from RV144 plasma samples resulted in 222 decreased Fc-mediated effector activities in vitro including significant decreases in 223 ADCC, ADP and the loss of Fc effector polyfunctionality, compared to undepleted samples [5]. 
226 During early HIV infection, functional Ab responses decline drastically with HIV

227 disease progression, which is correlated with waning IgG3 Ab concentrations [3, 61, 228 63]. In HIV-1 neutralization studies, polyclonal IgG3 Abs are more potent than any 229 other subclass [70], with increased length of the hinge region enhancing neutralization 230 potency and significantly improved phagocytosis and trogocytosis activity in vitro 231 compared to IgG1 [71]. Moreover, Env-binding monoclonal IgG3 Abs are more 232 effective at internalizing viral particles compared to Env-binding IgG1 of the same 233 specificity [72]. Thus, the maintenance of IgG3 Abs could be useful for both prevention 234 of HIV infection as well as for antiviral control. However, a recent study also identified $235 \lg 33$ as a regulator of $\operatorname{IgM}^{+}$tissue-like memory (TLM) B-cells, where $\operatorname{lgG}^{+} \operatorname{IgM}^{+} \mathrm{TLM}$ 236 B-cells from chronic HIV individuals, but not aviremic individuals, observed reduced 237 sensitivity to B cell receptor stimulation compared to their lgG3-lgM ${ }^{+}$counterparts [73].

238 This modulation of $\operatorname{lgM}^{+}$B-cell stimulation was reported to occur through multiple 239 mechanisms including, direct co-localization of $\lg G 3$ with $\lg \mathrm{M}$, along with interactions 240 with FcRIlb (inhibitory FcR), C1q and C-reactive protein [73]. IgG3 binding to the IgM-B241 cell receptors could also arise in the setting of persistent HIV viremia and contribute 242 to refractory $\operatorname{lgM}^{+} \mathrm{B}$-cell stimulation during chronic infection [73]. Furthermore, a recent 243 HIV cohort study also reported that IgG Fc polyfunctionality (ADCC, ADCP and 244 antibody dependant trogocytosis) and greater subclass diversity (i.e. induction of all 245 IgG subclasses and not IgG3 alone) were associated with the development of broadly neutralizing Abs (bNAbs) compared to HIV-individuals that failed to develop bNAbs

247 [74]. Further studies are needed to determine the advantages and disadvantages of 248 IgG3 responses during HIV infections, as well as any putative therapeutic applications, 249 especially in context of balancing chronic B-cell regulation, against the potential for 
eliciting highly functional IgG3 Abs with more potent anti-viral Fc effector functions and improved bNAb responses.

IgG3-mediated responses play a role in an array of other viral infections. One study

253 found that Chikungunya virus-specific responses are dominated by neutralizing IgG3

254 Abs, which developed rapidly in patients with high viremia [75]. In contrast, pre-existing IgG in patients, mainly lgG1 and IgG3, against severe Dengue virus (DENV) can form virus-Ab complexes with a different DENV serotype, promoting infection which can lead to complications, such as dengue hemorrhagic fever and dengue shock syndrome $[62,76,77]$. This cross-serotype activity is referred to as Ab-dependent enhancement (ADE), that is theorized to be due to higher antigen avidity [34], activation of complement [62], and FcyR binding [78, 79] compared to same serotype responses. IgG3 responses might also be detrimental in this scenario, because it bears the greatest potential to activate complement and initiate FcyR uptake by effector immune cells relative to any other subclass $[23,51]$. In a recent study, among monoclonal Abs (mAbs) recovered from survivors of Ebola virus infections, IgG3 Abs induced high-level ADE and FcyR blocking experiments with THP-1 cells, a monocytic cell line, showed that blocking of FcyRIII eliminated IgG3-mediated ADE completely, while blocking of FcyRI or FcyRII reduced it significantly [80].

\section{Bacterial Infections}

270 The IgG subclass distribution in anti-bacterial responses is more heterogeneous than

271 those produced in anti-viral responses due to the diversity of bacteria epitopes [46].

272 Limited studies have explored the importance of IgG3 in bacterial infections; however,

273 a key anti-bacterial property of human IgG3 Abs is their ability to induce CDC (Fig. 2)

274 [16]. Protection against the invasive Neisseria meningitidis has been found to depend 
on the recognition of bacterial surface antigens by Abs, activation of complement, and degradation of bacteria by bacteriolysis. Human IgG3 displayed higher bacteriolysis activity than IgG1 in vitro when the target antigen (FHbp) was sparsely expressed on wildtype bacteria (group B strain H44/76-WT) compared to a mutant bacteria that expressed three-fold more surface target antigen [8]. Additionally, this study showed that recombinant IgG3 mAbs, with shorter hinge regions, such as $\lg G 3 \mathrm{G} 3 \mathrm{~m} 15$, performed better than other IgG3 allotype mAbs, irrespective of Ab specificity, in enhancing complement-mediated bactericidal activity against $N$. meningitidis [8]. By contrast, the long hinge region of non-G3m15 lgG3 seems to dampen the high CDC capability of lgG3 Fc through an unknown mechanism in N. meningitidis infections [8]. It is therefore possible that lgG3 Abs with a shorter hinge region might be more effective in clearing $N$. meningitidis infections, and potentially other bacterial pathogens, but this remains to be further tested.

IgG3 are also potent mediators of opsonophagocytosis of bacterial pathogens. The uptake of Salmonella typhimurium by human monocytic THP-1 cells in vitro is greatest when the bacteria are opsonized with human $\lg G 3$, followed by $\lg \mathrm{G} 1$, IgG4 then $\lg G 2$ [81]. Similar results have been observed with $N$. meningitidis infections, where chimeric lgG3, isolated from plasma of vaccinees immunized with a meningococcal vaccine, is highly efficient in mediating phagocytosis after opsonisation, when using polymorphonuclear leucocytes as effector cells in the presence of human complement $[6,7]$.

298 However, it should be cautioned that high expression of IgG3-complement immune 299 complexes is not always advantageous to the host. For instance, IgG1 and IgG3 are 

the predominant human Ab subclasses formed against a Mycobacterium tuberculosis

$301(M t b)$ infection [82]. They stimulate the release of tumor necrosis factor (TNF) from 302 primary monocytes [83], enhance bacterial uptake by macrophages and form 303 complement immune complexes, which remain elevated during active TB, and 304 furthermore, have been associated with increased disease severity [84]. As a result, excessive IgG1 and IgG3 subclasses might potentially cause an excessive proinflammatory response, which in the case of active TB may be more harmful than

307 protective [84]. This argues for a complex role of IgG3 in bacterial infections including

308 both bacterial uptake and clearance and in $\mathrm{C1q}$ immune complex formation.

309 Consequently, this illustrates the need for extensive and robust studies that examine

310 the role of IgG3 Abs in relevant bacterial infections.

\section{Parasitic Infections}

313 The predominant IgG subclass produced in response to parasites like Plasmodium

314 falciparum are $\lg \mathrm{G} 1$ and $\lg \mathrm{g} 3$ [85]. $\lg \mathrm{g} 3$ is linked to protective immunity against 315 malaria $[11,12,85,86]$, due to opsonisation of malaria-infected erythrocytes and 316 promotion of Ab-dependent effector functions [10, 13, 87, 88]. In addition, they can

317 induce complement deposition at the merozoite stage of the parasite, thus mediating 318 inhibition of erythrocyte invasion [89-91]. IgG3-induced CDC is also associated with 319 anti-plasmodium sporozoite immunity in children [92]. In regards to Plasmodium 320 vivax merozoites, the predominant Abs produced are also IgG1 and IgG3 [93, 94].

321 Moreover, Abs against the classical $\alpha-G a l$ (Gala1-3Galß1-4GlcNAc-R) epitopes have 322 correlated with protection against Plasmodium spp. infections, reducing malaria 323 transmission by Anopheles mosquitoes [95]. In addition, higher a-Gal IgG3, but also 
$324 \operatorname{lgG} 4$ and IgM are associated with protection against clinical malaria in contrast to what

325 has been previously observed for other protein antigens [96].

327 IgG3 allotypes may also play a role in malaria susceptibility or protection. The

328 combination of homozygous G3m6 allotype and Km3 may protect against placental 329 malaria [97] and children with these allotypes have been reported to be better

330 protected against uncomplicated malaria than non-carriers [98]. However, other

331 studies have suggested that $\mathrm{G} 3 \mathrm{~m}$ but not $\mathrm{Km}$ allotypes might influence host

332 susceptibility to malaria infection together with the Ab profile of the donors $[99,100]$.

333 Individuals with the G3m6 allotype had a higher incidence of uncomplicated malaria

334 than non-carriers, due to low baseline IgG3 concentrations and high baseline of non335 cytophilic subclasses [99]. Of note, G3m6 is predominantly found in African 336 populations, possibly as a result of differential evolutionary selection caused by 337 infectious diseases such as malaria [100]. Evidently, further studies are needed to 338 validate any conclusions regarding general protection or susceptibility.

340 In a recent study in Beninese women, the H435-IgG3 polymorphism (i.e. allotypes

341 G3m15 and G3m16 which potentiate binding of IgG3 to FcRn) increased the trans342 placental transfer and half-life of malaria-specific IgG3 in young infants compared with 343 non-carriers and was associated with reduced risk of clinical malaria during infancy 344 [9]. The H435-IgG3 allele is most common in Africans (30\%-60\%), suggesting a 345 possible role for positive selection, given its relatively high frequency in malaria 346 endemic areas [9]. However, the G3m15 and G3m16 allotypes have also been 347 associated with increased susceptibility to the autoantibody-mediated disease 348 pemphigus vulgaris (PV), a severe blistering skin disorder, and thus, IgG3 might play 
a role in the pathogenesis of PV; alternatively, there may be a genetic association between H435-IgG3 alleles and PV in Middle Eastern and North African countries [101]. More research on lgG3 polymorphism frequencies in endemic populations may aid in the identification of potential selective advantages and disadvantages of these IgG3 polymorphisms [9].

\section{Potential of IgG3 for therapeutic applications}

\section{Current state of play}

By the end of 2018, there were approximately 80 approved therapeutic Abs (thAbs) on the market [102]. However, only three monoclonal thAbs are currently licensed for the treatment of infectious diseases (Palivizumab, a humanized lgG1 mAb against the respiratory syncytial virus (RSV) [103]; Raxibacumab, a humanized IgG1 mAb against Bacillus anthracis [104]; and Ibalizumab, a humanized IgG4 mAb, which inhibits HIV from entering host cells [105]). Currently, a limited number of IgG-based thAbs are in late-stage clinical studies for infectious indications [102, 106, 107]. Almost all thAbs to date have human IgG1 or IgG4 Fc domains, and there are presently no approved IgG3 thAbs [102]. Different reasons for this include : i) its extensive hinge region, which can contribute to increased proteolysis in vitro [108]; ii) the multiple IgG3 allotypes that exist across populations, including allo-immunity to foreign allotype polymorphisms [60], and iii) the reduced half-life of specific IgG3 allotypes [24]. Given the significance of IgG3 responses against natural infections and lgG's unique structural and functional characteristics, we emphasize the need to consider lgG3 properties when developing and testing new thAbs. The shorter half-life of IgG3 can be overcome by focusing on allotypes such as $\mathrm{G} 3 \mathrm{~m} 15$ and $\mathrm{G} 3 \mathrm{~m} 16$ with $\mathrm{H} 435$, or glycosylation patterns that prolong Ab half-life [24]. In a mouse model of Streptococcus pneumoniae infection, IgG3-H435 
demonstrated significantly better protection against S. pneumoniae than $\lg$ G1 and IgG3-R435, indicating that IgG3-H435 might be considered when devising future improved therapeutic approaches to treat infections in vivo, that aim to increase IgG3 serum longevity [24].

378

379 In the past, differences in allotypes of a thAb were thought to potentially contribute to therapeutic resistance due to the recognition of "non-self" Fc protein structures, potentially by enhancing clearance of the thAb or in the worst-case scenario, by becoming immunogenic and precipitating severe adverse reactions [109]. However, studies have now demonstrated that allotypic differences between IgG1 thAbs do not appear to produce novel T-cell epitopes in mismatched individuals, or induce 'nonself' anti-allotypic Abs and are unlikely to represent a significant risk factor for induction of immunogenicity $[110,111]$, but instead can improve the half-life of thAbs via FcRn binding [112]. Further studies, especially for IgG3 allotypes which have significantly greater polymorphisms and structural changes than $\lg \mathrm{G} 1$, are required before any allotype contributions to anti-thAb responses can be disregarded.

\section{Engineering therapeutic IgG3 Abs with enhanced functional properties}

A major advantage of thAbs, is their ability to promote Fc effector functions most relevant for clearance and control of a targeted pathogen $[113,114]$. Mounting evidence has identified key mutations in the $\operatorname{lgG} 1 \mathrm{Fc}$ domain of thAbs that can enhance the affinity to FcyR or complement $[113,114]$. However, as previously discussed, specific allotypes and structural properties of IgG3 Abs can enhance Fc effector functions, in a manner that is superior to that of IgG1. One study showed that 
ADCP and antibody dependent cellular trogocytosis) and neutralization potency of a broadly neutralizing anti-HIV Ab (CAP256-VRC26) compared to IgG1 in vitro [71].

401 Furthermore, the development of cross IgG subclass variants has yielded promising 402 results; namely, the combination of $\mathrm{C}_{\mathrm{H}} 1$ regions of $\lg \mathrm{G} 1$ with the $\mathrm{C}_{\mathrm{H}} 2$ and $\mathrm{C}_{\mathrm{H}} 3$ regions 403 of IgG3 can also enhance CDC activity relative to IgG1 [26]. Thus, we posit that next generation monoclonal thAbs should consider utilizing optimized Fc regions including some of the best features of IgG3, which provide its greater molecular flexibility and stronger affinity to FcyR and C1q. Moreover, the generation of bispecific and even polyspecific Abs is an exciting approach within the thAb community $[115,116]$. Bispecific and polyspecific IgG3, with its extended flexibility and reach in its Fab arms might potentially contribute to enhanced neutralization and avidity to pathogens relative to the other subclasses $[17,70,71,75]$. Thus, utilizing IgG3 as a backbone for

411 the design of polyspecific thAbs has the potential to enhance both the Fab and Fc 412 functionalities. Clearly, a more detailed understanding of $\lg G 3$ molecular and 413 functional properties may galvanize the engineering and development of effective 414 thAbs to treat a variety of conditions.

\section{Outstanding challenges and limitations}

417 The potential advantages and pathways forward for the development of $\lg G 3$ 418 monoclonal thAbs against infectious diseases, while a steep learning curve, also 419 appears to be relatively straight forward as many of the technologies have already 420 been developed to explore thAb with other subclass backbones, especially lgG1. By contrast, the steps towards the development of IgG3-centric vaccines are less clear.

422 One area where many questions remain, is to devise ways to elicit durable IgG3 concentrations in humans upon vaccination. IgG3 is only naturally $\sim 8 \%$ of total plasma 
$424 \lg$ [14]. Whether eliciting high IgG3 is possible, or even advisable, or whether

425 adjuvants would be required to achieve this (and which), is presently unknown. The

426 RV144 phase III HIV vaccine clinical trial, which elicited protective IgG3, had a very

427 short duration of protection within vaccinated individuals (60\% protection at 1 year, as

428 opposed to $31 \%$ by $\sim 2.5$ years) $[4,5,117]$. This highlights the need to rigorously

429 pursue current successful vaccines that can induce durable long lasting protection,

430 and which elicit high IgG3 concentrations; indeed solid examples include the need to

431 understand the mechanisms that lead to long lasting IgG3 serum Abs in response to

432 tetanus and meningococcal vaccines [6, 118].

433 Another example is that of the non-protective HIV vaccine trial (VAX003), where higher

434 IgG3 was induced at two months (into a six-month vaccination protocol) compared to

435 the moderately protective HIV RV144 trial at the same time point. However, the IgG

436 Abs elicited in VAX003 at two months were less functional than IgG3 elicited by RV144

437 [5]. The reason for this is still unclear, though the authors hypothesize that the role of

438 IgG3 glycosylation and IgG subclass balance may be essential [5]. Thus, this highlights another understudied area of research; namely, the importance of IgG3specific $\mathrm{N}$ - and O-glycosylation, and their modulation by vaccination. Future studies should also investigate whether glycans exert variable effects on different allotypes.

443 Another unknown dynamic is the balance between IgG3 Ab-mediated activation and over-activation. For instance, a recent study suggested that excessive IgG3 might lead

445 to negative regulation of TLM B-cells, resulting in refractory BCR signalling, as seen 446 in chronic HIV-infected individuals [73]. Similarly over induction of lgG3 effector 447 functions, such as ADCC have been reported to increase the severity of disease in 448 case of DENV [119] and have been suggested to be associated with excessive 
inflammatory responses in active TB [120].

450

451 A further challenge is the dearth of suitable animal models for studying IgG3 Abs and 452 their interaction with FcyRs, which are vital for understanding the role of IgG3 in the 453 pathogenesis, protection and vaccination against a range of infectious diseases.

454 Although there are significant differences between human and murine Abs in terms of 455 structures, capacity to activate complement [19] as well as between FcyR structures 456 and functions [121]. Thus, humanized mice which bear genetically engineered human 457 Igs [122] and human FcyRs [123]might help overcome some of these limitations . 458 Similarly, non-human primates harbour different IgG subclass binding properties 459 compared to humans [124]. This creates an obvious difficulty in translating immune 460 response findings in animal models to predicting human vaccination results, or thAb 461 trials [20]. Thus, Acknowledging the strengths and limitations of animal models and 462 working towards improving these may potentiate our understanding of IgG3 463 responses in infectious diseases, and better harness the possible benefits of IgG3464 based pharmaceuticals.

465

\section{Concluding remarks}

467 In summary, the critical role of IgG3 in the control and/or protection against a range of 468 infectious diseases is evident from the numerous studies highlighted herein [1-5, 9, $46996,125]$. This ability is mainly due to the inherit unique molecular properties of IgG3 470 which can confer highly functional potent effector responses. Although numerous 471 questions remain (see outstanding questions), increasing our molecular 472 understanding of IgG3 and its functional properties will improve the engineering and 
development of future next generation thAb and potentially expand our understanding of how to induce more protective IgG3-centric vaccines.

\section{Acknowledgements}

We thank Milla McClean and Ester Lopez for their assistance revising this manuscript.

This work was supported by funding from the University of Melbourne (TD), National Health and Medical Research Council of Australia (NHMRC) (SJR, SJK, AWC), by the Australian Centre for Research Excellence in Malaria Elimination (ACREME) (SJR) and the American Foundation for AIDS Research (amfAR) Mathilde Krim Fellowship (AWC).

Figure Legends:

490 Figure 1: Schematic overview of human IgG3 antibody. (a) $\lg$ G1-4 molecules consist of four polypeptide chains, composed of two identical $y$ heavy (green) chains of $50 \mathrm{kDa}$ and two identical light (yellow) chains of $25 \mathrm{KDa}$, linked together by inter-

493 chain disulfide bonds. Each heavy chain consists of an $\mathrm{N}$-terminal variable domain $494\left(\mathrm{~V}_{\mathrm{H}}\right)$ and three constant domains $\left(\mathrm{C}_{\mathrm{H}} 1, \mathrm{C}_{\mathrm{H}} 2, \mathrm{C}_{\mathrm{H}} 3\right)$. IgG molecules comprise similar495 sized globular portions joined by a flexible stretch of polypeptide chain between $\mathrm{C}_{\mathrm{H}} 1$ 496 and $\mathrm{C}_{\mathrm{H}} 2$, known as the 'hinge region'. The $\mathrm{V}_{\mathrm{H}}, \mathrm{C}_{\mathrm{H}} 1$ domains and the light chains form 497 the fragment antigen binding (Fab) regions [25]. The lower hinge region and the 
$498 \mathrm{C}_{\mathrm{H}} 2 / \mathrm{C}_{\mathrm{H}} 3$ domains form the fragment crystalline $(\mathrm{Fc})$ region, which interacts with

499 effector molecules and cells.

500 (b) Allotypes of IgG3 are polymorphisms to the constant regions on the $\mathrm{C}_{\mathrm{H}} 2$ and $\mathrm{C}_{\mathrm{H}} 3$

501 domains. The correlations between the most common G3m allotypes and amino acids

502 are shown. Positions in bold are according to the IMGT unique numbering for $\mathrm{C}$ 503 domain [126] and in italics for Eu numbering [127].

504 (c) Within the $\mathrm{C}_{\mathrm{H}} 2$ region is one $\mathrm{N}$-glycosylation site containing carbohydrate groups

505 attached to asparagine 297. The glycan has a heptasaccharide core (blue background

506 block) and variable extensions, such as fucose, galactose and/or sialic acid (dash

507 line). The glycosylation patterns in healthy human serum often includes fucosylated

508 glycoforms (red triangle) [128]. Additional $\mathrm{N}$-glycosylation sites have been reported in

509 the $V_{H}$ and $V_{L}$ of the variable region and IgG3-specific O-glycosylation sites in the

510 hinge region. Glycosylation of IgG varies with age, gender, disease state, infection,

511 and vaccination, reflecting the dynamic processes that can alter antibody effector

512 function as responses to infectious agents $[28,38,129]$.

513

514 Figure 2: Overview of human IgG3 properties and effector mechanisms. (Key

515 Figure)

516 Green background: $\lg G 3$ is associated with better activity than other $\lg G$ subclasses,

517 red background: IgG3 is associated with poorer outcomes compared to other IgG

518 subclasses.

519 * allotype-dependent

520 † shown in HIV-infected individuals [73] 
526 Table 1: Properties of human IgG subclasses.

\begin{tabular}{|c|c|c|c|c|}
\hline & $\operatorname{lgG} 1$ & $\lg$ 2 & $\lg$ G3 & $\operatorname{lgG} 4$ \\
\hline Heavy chain type & gamma 1 & gamma 2 & gamma 3 & gamma 4 \\
\hline Molecular mass (kD) & 146 & 146 & 170 & 146 \\
\hline Amino acids in hinge region & 15 & 12 & $62^{*}$ & 12 \\
\hline $\begin{array}{l}\text { Disulfide bonds in hinge } \\
\text { region }\end{array}$ & 2 & 4 & 11 & 2 \\
\hline Number of allotypes & $4(+2)$ & 1 & $13(+2)$ & 0 \\
\hline 'Classical' allotypes & $\begin{array}{l}\mathrm{G} 1 \mathrm{~m} 1,2 \\
3,17\end{array}$ & G2m23 & $\begin{array}{c}\text { G3m5, } 6,10,11,13,14,15 \\
16,21,24,26,27,28\end{array}$ & - \\
\hline 'Surnumerary' allotypes & $\mathrm{G} 1 \mathrm{~m} 27,28$ & - & G3m27, 28 & - \\
\hline Mean adult serum level (g/l) & 6.98 & 3.8 & 0.51 & 0.56 \\
\hline Proportion of total lgG (\%) & $43-75$ & $16-48$ & 1.7-7.5 & $0.8-11.7$ \\
\hline Half-life (days) & 21 & 21 & 7/ 21* & 21 \\
\hline Placental transfer & +++ & ++ & $++/+++*$ & ++ \\
\hline \multicolumn{5}{|l|}{ Antibody response to } \\
\hline Proteins & ++ & $+/-$ & ++ & $+/-$ \\
\hline Polysaccharides & + & ++ & $+/-$ & $+/-$ \\
\hline Allergens & + & $(-)$ & $(-)$ & ++ \\
\hline \multicolumn{5}{|l|}{ Complement activation } \\
\hline C1q binding & ++ & + & +++ & + \\
\hline \multicolumn{5}{|l|}{ Binding to FcyR } \\
\hline FcyRI & +++ & - & +++ & + \\
\hline FcyRlla & ++ & $+/-$ & ++ & $+/-$ \\
\hline FcyRIIb ${ }^{\dagger} / \mathrm{c}$ & ++ & $+/-$ & ++ & ++ \\
\hline FcyRIIla & + & $+/-$ & +++ & $+/-$ \\
\hline FcyRIIIb & $+/-$ & $+/-$ & + & - \\
\hline
\end{tabular}


FcRn $($ at $\mathrm{pH}<6.5)$

Binding to Staphylococcus

Protein A

Binding to Staphylococcus

Protein G

* allotype-dependent

† inhibitory

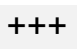

$++$

$++$

$++$
$+++$

$+$

$++$

527

528

529

530

531

532

533 
534 Table 2: Nomenclature of the six most prevalent human IgG3 $\mathrm{Gm}$ allotypes

535 shared among individuals within populations. Adapted from [10].

536

\begin{tabular}{|c|c|c|c|c|c|c|}
\hline $\begin{array}{c}\text { Allotype } \\
\text { (WHO } \\
\text { nomenclatur } \\
\text { e) }\end{array}$ & $\begin{array}{c}\text { Allotype } \\
\text { (previous } \\
\text { designation) }\end{array}$ & $\begin{array}{c}\text { Alleles } \\
\text { (WHO/IUIS } \\
\text { nomenclat } \\
\text { ure) }\end{array}$ & $\begin{array}{c}\text { Simplified } \\
\text { form }\end{array}$ & $\begin{array}{c}\text { IGHG3 } \\
\text { genes } \\
\text { (IMGT } \\
\text { nomenclatu } \\
\text { re) }\end{array}$ & $\begin{array}{l}\text { Ig heavy } \\
\text { domain } \\
\text { chain }\end{array}$ & $\begin{array}{c}\text { Prevalence } \\
\text { in ethnic } \\
\text { groups }\end{array}$ \\
\hline G3m5 & G3m(b1) & $\begin{array}{l}\text { G3m5, 10, } \\
11,13,14, \\
26,27\end{array}$ & $\mathrm{G} 3 \mathrm{~m}^{*}$ & $\begin{array}{l}\text { IGHG3*01, } \\
{ }^{*} 05,{ }^{*} 06, \\
{ }^{*} 07,{ }^{*} 09, \\
* 10,{ }^{*} 11,{ }^{*} 12\end{array}$ & $\mathrm{H}-\mathrm{\gamma} 3 \mathrm{CH}_{\mathrm{H}} 3$ & $\begin{array}{c}\text { European, } \\
\text { North } \\
\text { America, } \\
\text { African and } \\
\text { Asian }\end{array}$ \\
\hline G3m6 & G3m(c3) & $\begin{array}{l}\text { G3m5, } 6, \\
10,11,14, \\
26,27\end{array}$ & G3m6* & IGHG3*13 & $\mathrm{H}-\mathrm{y} 3 \mathrm{C}_{\mathrm{H}} 3$ & African \\
\hline G3m15 & G3m(s) & $\begin{array}{l}\text { G3m10, 11, } \\
13,15,27\end{array}$ & G3m15* & IGHG3*17 & $\mathrm{H}-\mathrm{\gamma}^{3} \mathrm{C}_{\mathrm{H}} 3$ & $\begin{array}{l}\text { Sub- } \\
\text { Saharan } \\
\text { with high } \\
\text { frequencies } \\
\text { in Khoisan }\end{array}$ \\
\hline G3m16 & $\mathrm{G} 3 \mathrm{~m}(\mathrm{t})$ & $\begin{array}{l}\text { G3m10, 11, } \\
13,15,16, \\
27\end{array}$ & G3m16* & $\begin{array}{l}\text { IGHG3*18, } \\
* 19\end{array}$ & $\mathrm{H}-\mathrm{\gamma} 3 \mathrm{C}_{\mathrm{H}} 2$ & $\begin{array}{c}\text { most } \\
\text { prevalent in } \\
\text { North East } \\
\text { Asians }\end{array}$ \\
\hline G3m21 & $\mathrm{G} 3 \mathrm{~m}(\mathrm{~g} 1)$ & $\begin{array}{l}\text { G3m21, 26, } \\
27,28\end{array}$ & G3m21* & $\begin{array}{l}\text { IGHG3*14, } \\
* 15,{ }^{*} 16\end{array}$ & $\mathrm{H}-\mathrm{\gamma} \mathrm{CH}_{\mathrm{H}}$ & $\begin{array}{c}\text { European, } \\
\text { North } \\
\text { American } \\
\text { and Asian }\end{array}$ \\
\hline
\end{tabular}




\begin{tabular}{|c|c|c|c|c|c|c|}
\hline G3m24 & G3m(c5) & $\begin{array}{l}\mathrm{G} 3 \mathrm{~m} 5,6,11, \\
24,26\end{array}$ & G3m24* & IGHG3*03 & $\mathrm{H}-\mathrm{\gamma} 3 \mathrm{C}_{\mathrm{H}} 3$ & (including \\
\hline
\end{tabular}

540 Glossary target cell by a cytotoxic effector cell through a non-phagocytic process.

- Antibody-dependent cellular inhibition (ADCI): a process, in which antibodies can inhibit Plasmodium growth in the presence of monocytes.

- Antibody-dependent cellular viral inhibition (ADCVI): Fcy-receptormediated antiviral activity, which occurs when antibody bound to virus-infected target cells engages FcyR-bearing effector cells, such as natural killer cells, monocytes or macrophages.

- Antibody-dependent phagocytosis (ADP): the process by which innate immune phagocytic effector cells e.g. neutrophils, macrophages, monocytes ingest or engulf other cells, organisms or particles.

- Allotype: amino acid differences in the constant region of either the heavy chain or light chain within a subclass of antibodies.

- Avidity: the overall sum of binding strength of multiple affinities, often used to describe the accumulated strength of the two antibody Fab arms with its antigens. 
- Bacteriolysis: the destruction of bacterial cells, can often be mediated by antibodies.

- Bispecific antibody: recombinant protein that can simultaneously bind to two different types of antigens.

- Broadly neutralizing antibody (bNAb): special type of antibodies that can recognize and block many strains of a particular virus from entering healthy cells.

- C-reactive protein: a protein produced by the liver in response to inflammation or infection.

- Class switch recombination: a process by which proliferating B-cells rearrange the constant region genes in the immunoglobulin heavy chain locus to switch from expressing one class of immunoglobulin to another.

- C1q: a protein complex involved in the complement system, which is part of the innate immune system.

- Complement activation: part of the innate immune system, which is responsible for a quick and non-specific clearance of pathogens by attracting phagocytic cells.

- Complement-dependent cytotoxicity (CDC): C1q binds an antibody, which triggers the complement cascade, as a result of the classical pathway complement activation.

- Envelope (Env) protein: a protein expressed on the surface of enveloped viruses.

- Fab region: domain on an antibody that binds to antigens, involved in neutralization. 
- Fc region: tail region of an antibody that determines innate immune effector function.

- Fcy-receptors (FcyRs): are surface protein receptors, defined as either activating receptors (FcyRI, FcyRIla/c, FcyRIII) or inhibitory receptor (FcyRIIb) as they elicit or inhibit immune functions.

- Glycosylation: a post-translational modification, whereby carbohydrates are attached to proteins (e.g. antibodies) through the aid of certain enzymes.

- Half-life: a measure of the mean survival time of a molecule to reduce to half its initial value.

- Hinge region: a flexible amino acid sequence in the central part of the heavy chains of the antibodies; can be linked by disulfide bonds.

- Isotype switching: the mechanism that changes the B-cell production of an immunoglobulin from one isotype to another.

- Monoclonal antibody (mAb): antibody produced by a single clone of cells.

- Neonatal Fc receptors (FcRn): MHC class I like molecule that functions to protect IgG from catabolism, mediates transport of IgG across epithelial cells, and is involved in antigen presentation.

- Opsonophagocytosis: a process by which the pathogen is marked by an opsonin, e.g. an antibody, for ingestion and eliminated by the phagocytes.Polymorphism: the occurrence of different forms among the members of a population or colony, or in the life cycle of an individual organism. types of antigens.

- Somatic hypermutation (SHM): a process that diversifies B-cell receptors to better recognize antigens and produce antibodies against pathogens. 
608 - Toll-like receptors: expressed on sentinel cells such as macrophages and

609 dendritic cells, that recognize structurally conserved molecules derived from $610 \quad$ pathogens.

611 - Trogocytosis: the transfer of plasma membrane fragments from target cell 612 to the effector cell.

613 - Uncomplicated malaria: symptomatic malaria without signs of severity or 614 evidence of vital organ dysfunction.

615 - V(D)J recombination: a unique mechanism of genetic recombination that 616 occurs only during the early stages of T-and B-cell maturation.

617

618

619 
621 1. Ackerman, M.E. et al. (2016) Polyfunctional HIV-Specific Antibody Responses Are

622 Associated with Spontaneous HIV Control. PLoS Pathog 12 (1), e1005315.

623 2. Chung, A.W. et al. (2015) Dissecting Polyclonal Vaccine-Induced Humoral Immunity

624 against HIV Using Systems Serology. Cell 163 (4), 988-98.

625 3. Sadanand, S. et al. (2018) Temporal variation in HIV-specific IgG subclass antibodies

626 during acute infection differentiates spontaneous controllers from chronic progressors. AIDS

$62732(4), 443-50$.

628 4. Yates, N.L. et al. (2014) Vaccine-induced Env V1-V2 IgG3 correlates with lower HIV-1

629 infection risk and declines soon after vaccination. Sci Transl Med 19 (6), 228.

630 5. Chung, A.W. et al. (2014) Polyfunctional Fc-effector profiles mediated by IgG subclass

631 selection distinguish RV144 and VAX003 vaccines. Sci Transl Med 6 (228), 228ra38.

632 6. Aase, A. et al. (1998) Opsonophagocytic and Bactericidal Activity Mediated by Purified

633 IgG Subclass Antibodies After Vaccination with the Norwegian Group B Meningococcal

634 Vaccine. Scand J Immunol 47, 388-96.

635 7. Vidarsson, G. et al. (2001) Activity of human IgG and IgA subclasses in immune defense

636 against Neisseria meningitidis serogroup B. J Immunol 166 (10), 6250-6.

637 8. Giuntini, S. et al. (2016) Human IgG1, IgG3, and IgG3 Hinge-Truncated Mutants Show

638 Different Protection Capabilities against Meningococci Depending on the Target Antigen and

639 Epitope Specificity. Clin Vaccine Immunol 23 (8), 698-706.

640 9. Dechavanne, C. et al. (2017) Associations between an IgG3 polymorphism in the binding

641

642

643

644

645

646

647

648

649

650

651

652

653

654

655

656

657

658

659

660

661

662

663

664

665 domain for FcRn, transplacental transfer of malaria-specific IgG3, and protection against Plasmodium falciparum malaria during infancy: A birth cohort study in Benin. PLoS Med 14 (10), e1002403.

10. Kana, I.H. et al. (2018) Cytophilic Antibodies Against Key Plasmodium falciparum Blood Stage Antigens Contribute to Protection Against Clinical Malaria in a High Transmission Region of Eastern India. J Infect Dis 218 (6), 956-965.

11. Stanisic, D.I. et al. (2009) Immunoglobulin G subclass-specific responses against Plasmodium falciparum merozoite antigens are associated with control of parasitemia and protection from symptomatic illness. Infect Immun 77 (3), 1165-74.

12. Weaver, R. et al. (2016) The association between naturally acquired IgG subclass specific antibodies to the PfRH5 invasion complex and protection from Plasmodium falciparum malaria Sci Rep 6, 33094.

13. Osier, F.H.A. et al. (2014) Opsonic phagocytosis of Plasmodium falciparum merozoites: mechanism in human immunity and a correlate of protection against malaria. BMC Medicine 12 (108).

14. Lefranc, G. and Lefranc, M.-P. (2001) The Immunoglobulin FactsBook, Academic Press. 15. Pumphrey, R.S.H. (1986) Computer models of the human immunoglobulins: Binding sites and molecular interactions. Immunol Today 7 (7-8), 206-11.

16. Carrasco, B. et al. (2001) Crystallohydrodynamics for solving the hydration problem for multi-domain proteins: open physiological conformations for human IgG. Biophys Chem 93 (2-3), 181-96.

17. Vidarsson, G. et al. (2014) IgG subclasses and allotypes: from structure to effector functions. Front Immunol 5 (520).

18. Roux, K.H. et al. (1997) Flexibility of human IgG subclasses. J Immunol 159 (7), 337282.

666 19. Bruhns, P. (2012) Properties of mouse and human IgG receptors and their contribution to 667 disease models. Blood 14 (119), 5640-9.

668 20. Chan, Y.N. et al. (2016) IgG Binding Characteristics of Rhesus Macaque FcgammaR. J

669 Immunol 197 (7), 2936-47. 

antigens in non-human primates. J Immunol 113 (2), 635-44.

672 22. Lefranc, M.-P. and Lefranc, G. (2012) Human Gm, Km and Am allotypes and their molecular characterization: a remarkable demonstration of polymorphism. Methods Mol Biol $674882,635-80$.

675 23. Bruhns, P. et al. (2009) Specificity and affinity of human Fcgamma receptors and their 676 polymorphic variants for human IgG subclasses. Blood 113 (16), 3716-25.

677 24. Stapleton, N.M. et al. (2011) Competition for FcRn-mediated transport gives rise to short half-life of human IgG3 and offers therapeutic potential. Nat Commun 2 (599). 25. Rispens, T. et al. (2014) Dynamics of inter-heavy chain interactions in human immunoglobulin G (IgG) subclasses studied by kinetic Fab arm exchange. J Biol Chem 289 (9), 6098-109.

26. Natsume, A. et al. (2008) Engineered antibodies of IgG1/IgG3 mixed isotype with enhanced cytotoxic activities. Cancer Res 68 (10), 3863-72.

27. Zwolak, A. et al. (2017) Rapid Purification of Human Bispecific Antibodies via Selective Modulation of Protein A Binding. Sci Rep 7 (1), 15521.

28. Mahan, A.E. et al. (2016) Antigen-Specific Antibody Glycosylation Is Regulated via Vaccination. PLoS Pathog 12, e1005456.

29. van de Bovenkamp, F.S. et al. (2018) Adaptive antibody diversification through N-linked glycosylation of the immunoglobulin variable region. PNAS 115 (8), 1901-1906.

30. Mimura, Y. et al. (2000) The influence of glycosylation on the thermal stability and effector function expression of human IgG1-Fc: properties of a series of truncated glycoforms. Mol Immunol 37 (12-13), 697-706.

31. Lee, C.-H. et al. (2017) IgG Fc domains that bind C1q but not effector Fcg receptors delineate the importance of complement-mediated effector functions. Nat Immunol 18 (8), 889-98.

32. Subedi, G.P. and Barb, A.W. (2015) The structural role of antibody N-glycosylation in receptor interactions. Structure 23 (9), 1573-83.

33. Lin, C.W. et al. (2015) A common glycan structure on immunoglobulin G for enhancement of effector functions. Proc Natl Acad Sci U S A 112 (34), 10611-6. 34. Wang, T.T. et al. (2017) IgG antibodies to dengue enhanced for Fc $\gamma$ RIIIA binding determine disease severity. Science 355 (6323), 369-8.

35. Niwa, R. et al. (2005) IgG subclass-independent improvement of antibody-dependent cellular cytotoxicity by fucose removal from Asn297-linked oligosaccharides. J Immunol Methods 306 (1-2), 151-60.

36. Chung, A.W. et al. (2014) Identification of antibody glycosylation structures that predict monoclonal antibody Fc-effector function. AIDS 28 (17), 2523-30.

37. Ho, C.H. et al. (2015) Aberrant Serum Immunoglobulin G Glycosylation in Chronic Hepatitis B Is Associated With Histological Liver Damage and Reversible by Antiviral Therapy. J Infect Dis 211 (1), 115-124.

38. Gardinassi, L.G. et al. (2014) Clinical Severity of Visceral Leishmaniasis Is Associated with Changes in Immunoglobulin G Fc N-Glycosylation. mBio 5 (6), e01844-14. 39. Lu, L.L. et al. (2016) A Functional Role for Antibodies in Tuberculosis. Cell 167, 433-43. 40. Vadrevu, S.K. et al. (2018) Frontline Science: Plasma and immunoglobulin G galactosylation associate with HIV persistence during antiretroviral therapy. J Leukoc Biol 104 (3), 461-471.

41. Quast, I. et al. (2015) Sialylation of IgG Fc domain impairs complement-dependent cytotoxicity. J Clin Invest 125 (11), 4160-70.

42. Kaneko, Y. et al. (2006) Anti-inflammatory activity of immunoglobulin G resulting from Fc sialylation. Science 313 (5787), 670-3. 
43. van de Bovenkamp, F.S. et al. (2018) Variable Domain N-linked glycans acquired During antigen-specific immune responses can contribute to immunoglobulin $\mathrm{G}$ antibody stability. Front Immunol 9.

44. Plomp, R. et al. (2015) Hinge-Region O-Glycosylation of Human Immunoglobulin G3 (IgG3). Mol Cell Proteomics 14 (5), 1373-84.

45. Julenius, K. et al. (2005) Prediction, conservation analysis, and structural characterization of mammalian mucin-type O-glycosylation sites. Glycobiology 15 (2), 153-64.

46. Ferrante, A., L. et al. (1990) IgG subclass distribution of antibodies to bacterial and viral antigens. Pediatr Infect Dis J 9 (16).

47. Schauer, U. et al. (2003) Levels of Antibodies Specific to Tetanus Toxoid, Haemophilus influenzae Type b, and Pneumococcal Capsular Polysaccharide in Healthy Children and Adults. Clin Diagn Lab Immunol 10 (2), 202-7.

48. Nouri-Aria, K.T. et al. (2004) Grass pollen immunotherapy induces mucosal and peripheral IL-10 responses and blocking IgG activity. J Immunol 172 (5), 3252-9. 49. Arnold, J.N. et al. (2006) Mannan binding lectin and its interaction with immunoglobulins in health and in disease. Immunol Lett 106, 103-10.

50. Malhotra, R. et al. (1995) Glycosylation changes of IgG associated with rheumatoid arthritis can activate complement via the mannose-binding protein. Nat Med 1 (3), 237-43. 51. Lu, Y.L. et al. (2007) Solution conformation of wild-type and mutant IgG3 and IgG4 immunoglobulins using crystallohydrodynamics: Possible implications for complement activation. Biophys J 93 (11), 3733-3744.

52. Thommesen, J.F. et al. (2000) Lysine 322 in the human IgG3 CH2 domain is crucial for antibody dependent complement activation. Mol Immunol 37, 995-1004.

53. Kapur, R. et al. (2014) IgG-effector functions: "The Good, The Bad and The Ugly". Immunol Lett 160 (2), 139-144.

54. McLean, M.R. et al. (2017) Dimeric Fc gamma Receptor Enzyme-Linked Immunosorbent Assay To Study HIV-Specific Antibodies: A New Look into Breadth of Fc gamma Receptor Antibodies Induced by the RV144 Vaccine Trial. J Immunol 199 (2), 816826.

55. Chung, A.W. et al. (2011) Activation of NK cells by ADCC antibodies and HIV disease progression. J Acquir Immune Defic Syndr 58 (2), 127-31.

56. Joos, C. et al. (2015) Antibodies to Plasmodium falciparum merozoite surface protein1 p19 malaria vaccine candidate induce antibody-dependent respiratory burst in human neutrophils. Malar J 14, 409.

57. Firan, M. et al. (2001) The MHC class I-related receptor, FcRn, plays an essential role in the maternofetal transfer of $\gamma$-globulin in humans. Int Immunol 13 (8), 993-1002.

58. Pyzik, M. et al. (2015) FcRn: The Architect Behind the Immune and Nonimmune Functions of IgG and Albumin. J Immunol 194 (10), 4595-603.

59. Shah, I.S. et al. (2017) Structural characterization of the Man5 glycoform of human IgG3 Fc. Mol Immunol 92, 28-37.

60. Einarsdottir, H. et al. (2014) H435-containing immunoglobulin G3 allotypes are transported efficiently across the human placenta: implications for alloantibody-mediated diseases of the newborn. Transfusion 54 (3), 665-71.

61. Dugast, A.S. et al. (2014) Independent evolution of Fc- and Fab-mediated HIV-1-specific antiviral antibody activity following acute infection. Eur J Immunol 44 (10), 2925-37.

62. Posadas-Mondragón, A. et al. (2017) Indices of anti-dengue immunoglobulin G subclasses inadult Mexican patients with febrile and hemorrhagicdengue in the acute phase. Mircobiol Immunol 61, 433-41.

63. Yates, N.L. et al. (2011) Multiple HIV-1-specific IgG3 responses decline during acute HIV-1: implications for detection of incident HIV infection. AIDS 25 (17), 2089-97.

64. Horns, F. et al. (2016) Lineage tracing of human B cells reveals the in vivo landscape of human antibody class switching. Elife 5. 
65. Kitaura, K. et al. (2017) Different Somatic Hypermutation Levels among Antibody

Subclasses Disclosed by a New Next-Generation Sequencing-Based Antibody Repertoire Analysis. Front Immunol 8, 389. 66. Pene, J. et al. (2004) Cutting edge: IL-21 is a switch factor for the production of IgG1 and IgG3 by human B cells. J Immunol 172 (9), 5154-7. 67. Malisan, F. et al. (1996) Interleukin-10 induces immunoglobulin $\mathrm{G}$ isotype switch recombination in human CD40-activated naive B lymphocytes. J Exp Med 183 (3), 937-47. 68. Briere, F. et al. (1994) Human interleukin 10 induces naive surface immunoglobulin D+ $(\mathrm{sIgD}+) \mathrm{B}$ cells to secrete IgG1 and IgG3. J Exp Med 179 (2), 757-62. Fujieda, S. et al. (1995) IL-4 plus CD40 monoclonal antibody induces human B cells gamma subclass-specific isotype switch: switching to gamma 1, gamma 3 , and gamma 4 , but not gamma 2. J Immunol 155 (5), 2318-28.

70. Scharf, O. et al. (2001) Immunoglobulin G3 from Polyclonal Human Immunodeficiency Virus (HIV) Immune Globulin Is More Potent than Other Subclasses in Neutralizing HIV Type 1. J Virol 75 (14), 6558-65.

71. Richardson, S. et al., IgG3 Hinge Length Enhances Neutralization Potency and Fc Effector Function of an HIV V2-specific Broadly Neutralizing Antibody, HIV Research for Prevention, Madrid, 2018.

72. Tay, M.Z. et al. (2016) Antibody-Mediated Internalization of Infectious HIV-1 Virions Differs among Antibody Isotypes and Subclasses. PLoS Pathog 12 (8), e1005817.

73. Kardava, L. et al. (2018) IgG3 regulates tissue-like memory B cells in HIV-infected individuals. Nat Immunol.

74. Richardson, S.I. et al. (2018) HIV-specific Fc effector function early in infection predicts the development of broadly neutralizing antibodies. PLoS Pathog 14 (4), e1006987.

75. Kam, Y.-W. et al. (2012) Early Appearance of Neutralizing Immunoglobulin G3 Antibodies is Associated with Chikungunya Virus Clearance and Long-term Clinical Protection. J Infect Dis 205 (7), 1147-54.

76. Syenina, A. et al. (2015) Dengue vascular leakage is augmented by mast cell degranulation mediated by immunoglobulin Fc $\gamma$ receptors. eLife 4, e05291.

77. Rodrigo, W.W. et al. (2010) Dengue virus neutralization is modulated by IgG antibody subclass and Fc $\gamma$ receptor subtype. Virology 394 (2), 175-82.

78. Ayala-Nunez, N.V. et al. (2016) How antibodies alter the cell entry pathway of dengue virus particles in macrophages. Sci Rep 6 (28768).

79. Wang, T.T. et al. (2017) IgG antibodies to dengue enhanced for FcgammaRIIIA binding determine disease severity. Science 355 (6323), 395-398.

80. Kuzmina, N.A. et al. (2018) Antibody-Dependent Enhancement of Ebola Virus Infection by Human Antibodies Isolated from Survivors. Cell Rep 24 (7), 1802-1815 e5.

81. Goh, Y.S. et al. (2011) Human IgG isotypes and activating Fc $\gamma$ receptors in the interaction of Salmonella enterica serovar Typhimurium with phagocytic cells. Immunology 133 (1), 74-83.

82. Sousa, A.O. et al. (1998) IgG subclass distribution of antibody responses to protein and polysaccharide mycobacterial antigens in leprosy and tuberculosis patients. Clin Exp Immunol 111 (1), 48-55.

83. Hussain, R. et al. (2000) PPD-specific IgG1 antibody subclass upregulate tumour necrosis factor expression in PPD-stimulated monocytes: possible link with disease pathogenesis in tuberculosis. Clin Exp Immunol 119 (3), 449-55.

84. Cai, Y. et al. (2014) Increased complement C1q level marks active disease in human tuberculosis. PLoS One 9 (3), 92340.

85. Richards, J.S. et al. (2010) Association between naturally acquired antibodies to erythrocyte-binding antigens of Plasmodium falciparum and protection from malaria and high-density parasitemia. Clin Infect Dis 51 (8), 50-60. 
86. Roussilhon, C. et al. (2007) Long-term clinical protection from falciparum malaria is strongly associated with IgG3 antibodies to merozoite surface protein 3. PLoS Med 4 (11), e320.

87. Mathiesen, L. et al. (2013) Maternofetal trans-placental transport of recombinant IgG antibodies lacking effector functions. Blood 122 (7), 1174-81.

88. Stubbs, J. et al. (2011) Strain-transcending Fc-dependent killing of Plasmodium falciparum by merozoite surface protein 2 allele-specific human antibodies. Infect Immun 79 (3), 1143-52.

89. Boyle, M.J. et al. (2015) Human antibodies fix complement to inhibit Plasmodium falciparum invasion of erythrocytes and are associated with protection against malaria. Immunity 42 (3), 580-90.

90. Joos, C. et al. (2010) Clinical protection from falciparum malaria correlates with neutrophil respiratory bursts induced by merozoites opsonized with human serum antibodies. PLoS One 5 (3), e9871.

91. Larsen, M.D. et al., Malaria parasite evasion of classical complement pathway European Meeting on Complement in Human Disease, 2017, Molecular Immunology, 2017, p. 159. 92. Kurtovic, L. et al. (2018) Human antibodies activate complement against Plasmodium falciparum sporozoites, and are associated with protection against malaria in children. BMC Med 16 (1), 61.

93. Fernandez-Becerra, C. et al. (2010) Naturally-acquired humoral immune responses against the N- and C-termini of the Plasmodium vivax MSP1 protein in endemic regions of Brazil and Papua New Guinea using a multiplex assay. Malar J 9.

94. Lima-Junior, J.C. et al. (2011) B cell epitope mapping and characterization of naturally acquired antibodies to the Plasmodium vivax merozoite surface protein-3alpha (PvMSP3alpha) in malaria exposed individuals from Brazilian Amazon. Vaccine 29 (9), 1801-11. 95. Yilmaz, B. et al. (2014) Gut Microbiota Elicits a Protective Immune Response against Malaria Transmission. Cell 159 (6), 1277-89.

96. Aguilar, R. et al. (2018) Antibody responses to $\alpha$-Gal in African children vary with age and site and are associated with malaria protection. Sci Rep 8 (9999), DOI:10.1038/s41598018-28325-w.

97. Iriemenam, N.C. et al. (2013) Association between Immunoglobulin GM and KM Genotypes and Placental Malaria in HIV-1 Negative and Positive Women in Western Kenya. PLoS One 8 (1), e53948.

98. Migot-Nabias, F. et al. (2008) Imbalanced distribution of GM immunoglobulin allotypes according to the clinical presentation of Plasmodium falciparum malaria in Beninese children. J Infect Dis 198 (12), 1892-5.

99. Giha, H.A. et al. (2009) Antigen-specific influence of GM/KM allotypes on IgG isotypes and association of GM allotypes with susceptibility to Plasmodium falciparum malaria. Malar J 8, 306.

100. Pandey, J.P. et al. (2007) Significant differences in GM allotype frequencies between two sympatric tribes with markedly differential susceptibility to malaria. Parasite Immunol 29 (267-9).

101. Recke, A. et al. (2018) The p.arg435his variation of IgG3 with high affinity to FcRn is associated with susceptibility for Pemphigus Vulgaris - analysis of four different ethnic cohorts. Front Immunol 9 (1788).

102. Kaplon, H.K. and Reichert, J.M. (2018) Antibodies to watch in 2019. MAbs.

103. Synagis (palivizumab). Full prescribing information, MedImmune, LLC, Gaithersburg, MD, 2014.

104. Mazumdar, S. (2009) Raxibacumab. MAbs 1 (6), 531-8.

105. Weinheimer, S. et al., Ibalizumab susceptibility in patient HIV isolates resistant to antiretrovirals, 25th Conference on Retroviruses and Opportunistic Infections (CROI 2018), Boston, US, 2018. 
877 107. Desoubeaux, G. et al., Therapeutic antibodies and infectious diseases, Tours, France,

878 November 20-22, 2012, mAbs, 2013, pp. 626-32.

879 108. Lakbub, J.C. et al. (2016) Disulfide Bond Characterization of Endogenous IgG3

880 Monoclonal Antibodies Using LC-MS: An Investigation of IgG3 Disulfide-mediated

881 Isoforms. Anal Methods 8 (31), 6045-55.

882 109. Magdelaine-Beuzelin, C. et al. (2009) IgG1 heavy chain-coding gene polymorphism

883 (G1m allotypes) and development of antibodies-to-infliximab. Pharmacogenet Genomics 19

884 (5), 383-7.

885 110. Bartelds, G.M. et al. (2010) Surprising negative association between IgG1 allotype

886

887

888

889

890

891

892

893

894

895

896

897

898

899

900

901

902

903

904

905

906

907

908 disparity and anti-adalimumab formation: a cohort study. Arthritis Res Ther 12, R221. 111. Webster, C.I. et al. (2016) A comparison of the ability of the human IgG1 allotypes G1m3 and G1m1,17 to stimulate T-cell responses from allotype matched and mismatched donors. MAbs 8 (2), 253-63.

112. Ternant, D. et al. (2016) IgG1 Allotypes Influence the Pharmacokinetics of Therapeutic Monoclonal Antibodies through FcRn Binding. J Immunol 196 (2), 607-13.

113. Lazar, G.A. et al. (2006) Engineered antibody Fc variants with enhanced effector function. Proc Natl Acad Sci U S A 103 (11), 4005-10.

114. Moore, G.L. et al. (2010) Engineered Fc variant antibodies with enhanced ability to recruit complement and mediate effector functions. MAbs 2 (2), 181-9.

115. Huang, Y. et al. (2016) Engineered Bispecific Antibodies with Exquisite HIV-1Neutralizing Activity. Cell 165 (7), 1621-31.

116. Mahlangu, J. et al. (2018) Emicizumab Prophylaxis in Patients Who Have Hemophilia A without Inhibitors. N Engl J Med 379, 811-22.

117. Robb, M.L. et al. (2012) Risk behaviour and time as covariates for efficacy of the HIV vaccine regimen ALVAC-HIV (VCP1521) and AIDSVAX B/E: a post-hoc analysis of the Thai phase 3 efficacy trial RV 144. Lancet Infect Dis 12 (7), 531-537.

118. Cooper, P.J. et al. (1999) Human Onchocerciasis and Tetanus Vaccination: Impact on the Postvaccination Antitetanus Antibody Response. Infect Immun 67 (11), 5951-7. 119. Garcia, G. et al. (2006) Antibodies from patients with dengue viral infection mediate cellular cytotoxicity. J Clin Virol 37 (1), 53-7.

120. de Araujo, L.S. et al. (2018) IgG subclasses' response to a set of mycobacterial antigens in different stages of Mycobacterium tuberculosis infection. Tuberculosis 108, 70-76.

121. Nimmerjahn, F. et al. (2005) Fc gamma RIV: A novel FcR with distinct IgG subclass specificity. Immunity 23 (1), 41-51.

122. Murphy, A.J. et al. (2014) Mice with megabase humanization of their immunoglobulin genes generate antibodies as efficiently as normal mice. PNAS 111 (14), 5153-5158.

123. Smith, P. et al. (2012) Mouse model recapitulating human Fcgamma receptor structural and functional diversity. Proc Natl Acad Sci U S A 109 (16), 6181-6.

124. Trist, H.M. et al. (2014) Polymorphisms and Interspecies Differences of the Activating and Inhibitory Fc $\gamma$ RII of Macaca nemestrina Influence the Binding of Human IgG

Subclasses. J Immunol 192, 792-803.

125. Kana, I.H. et al. (2017) Naturally acquired antibodies target the glutamate-rich protein on intact merozoites and predict protection against febrile malaria. J Infect Dis 215 (4), 62330 .

126. Lefranc, M.P. et al. (2005) IMGT unique numbering for immunoglobulin and T cell receptor constant domains and Ig superfamily C-like domains. Dev Comp Immunol 29 (3), 185-203.

127. Lefranc, M.P. et al. (2009) IMGT, the international ImMunoGeneTics information system. Nucleic Acids Res 37 (Database issue), D1006-12. 
926 128. Plomp, R. et al. (2017) Subclass-specific IgG glycosylation is associated with markers 927 of inflammation and metabolic health. Scientific Reports 7.

928 129. Ackerman, M.E. et al. (2013) Natural variation in Fc glycosylation of HIV-specific 929 antibodies impacts antiviral activity. J. Clin. Investig 123, 2183-92. 
(a)

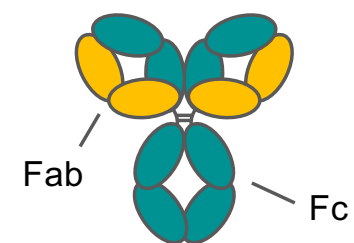

$\lg G 1$

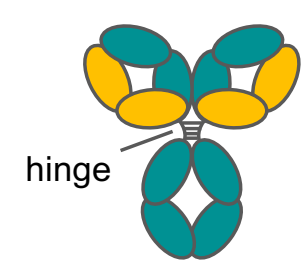

$\lg G 2$

(b)

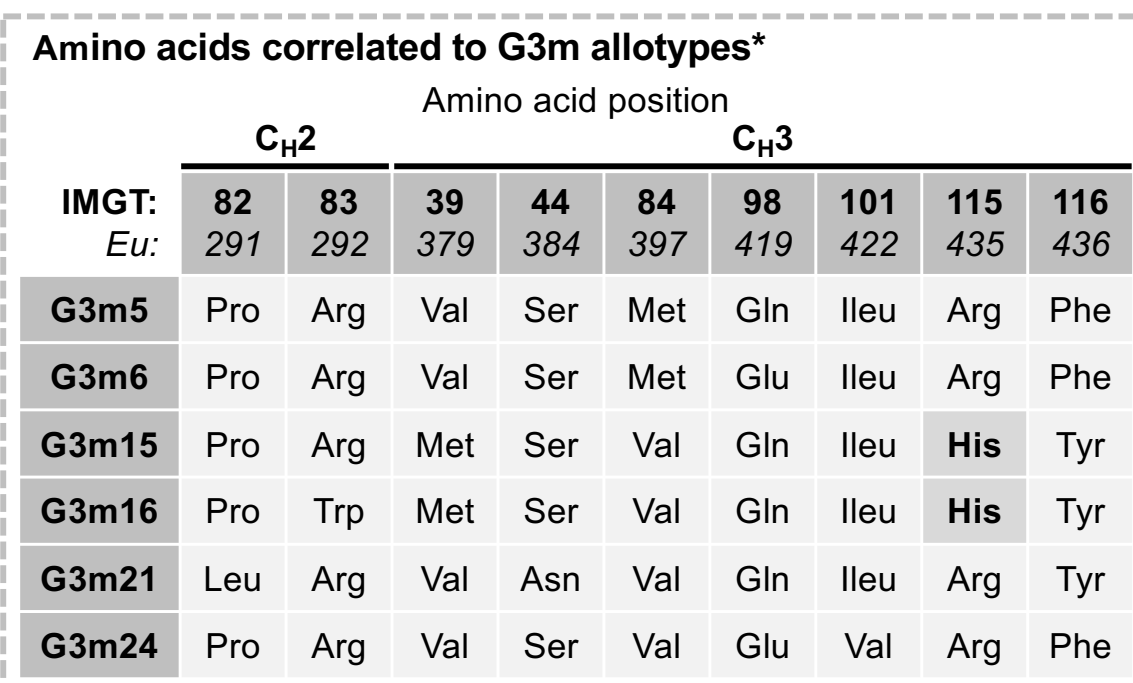

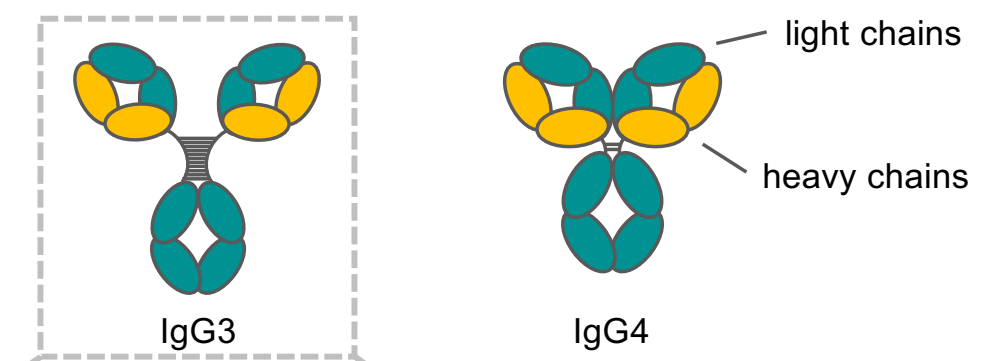

(c)
N-linked glycosylation sites

(Asn297 in $\mathrm{C}_{\mathrm{H}} 2 ; \mathrm{V}_{\mathrm{H}}+\mathrm{V}_{\mathrm{L}}$ )

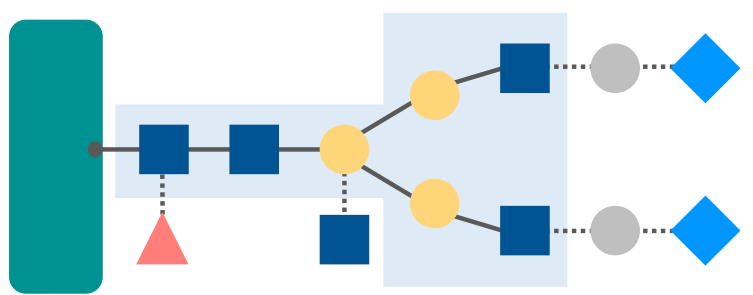

\section{O-linked glycosylation sites}

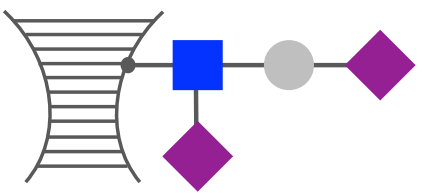
heptasaccharide core
$\Delta$ fucose
variable extensions
- galactose
- sialic acid
- N-acetylglucosamine
- N-acetylgalactosamine mannose
- N-acetylneuraminic acid 


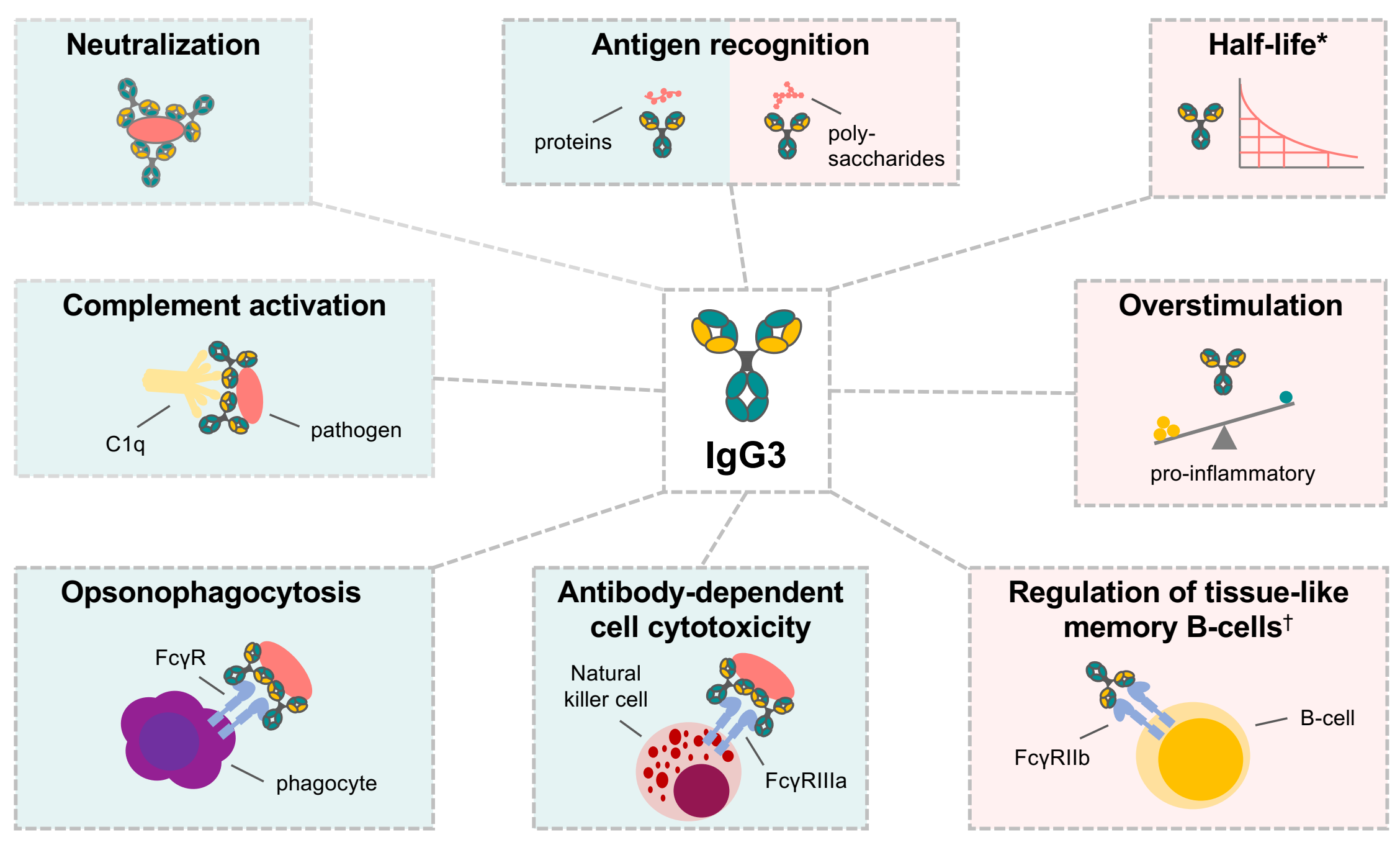




\section{University Library}

\section{- M M I E R R V A gateway to Melbourne's research publications}

Minerva Access is the Institutional Repository of The University of Melbourne

Author/s:

Damelang, T;Rogerson, SJ;Kent, SJ;Chung, AW

Title:

Role of IgG3 in Infectious Diseases

Date:

2019-03-01

Citation:

Damelang, T., Rogerson, S. J., Kent, S. J. \& Chung, A. W. (2019). Role of IgG3 in Infectious Diseases. TRENDS IN IMMUNOLOGY, 40 (3), pp.197-211. https://doi.org/10.1016/ j.it.2019.01.005.

Persistent Link:

http://hdl.handle.net/11343/284299 